\title{
IL28B genotype predicts response to chronic hepatitis $C$ triple therapy with telaprevir or boceprevir in treatment naïve and treatment-experienced patients other than prior partial- and null-responders
}

\author{
Giorgio Calisti ${ }^{*}$, Amanda Tavares $^{1}$, Malcolm J Macartney ${ }^{1}$, Adele McCormick' ${ }^{1}$, Wendy Labbett ${ }^{1}$, \\ Michael Jacobs², Geoffrey Dusheiko², William M Rosenberg ${ }^{2}$ and Tanzina Haque ${ }^{1}$
}

\begin{abstract}
Single nucleotide polymorphisms (SNPS) in the IL28B gene were shown to have limited utility in predicting response to telaprevir and boceprevir in treatment of chronic HCV infection in clinical trials. Data outside of the clinical trial setting are lacking. We assessed the value of single and combined IL28B SNPs rs12979860 and rs8099917 genotypes in predicting sustained virological response 12 weeks after cessation of triple therapy (SVR12) with telaprevir or boceprevir in a single-centre cohort of treatment-naïve and treatment-experienced patients with genotype $1 \mathrm{HCV}$ mono-infection $(n=105)$. The overall SVR12 rate was $65.7 \%$. By unadjusted bivariate logistic regression analysis, rs12979860-CC and rs8099917-TT were significantly associated with SVR12 in the subgroup of patients including all naiive patients and all treatment-experienced patients with the exception of partial- and null-responders to previous HCV therapy. The predictive value of rs12979860-CC was stronger than rs8099917-TT and only rs 12979860-CC remained significantly predictive of treatment success when the two variants were assessed by adjusted logistic regression analysis in the whole study cohort. In patients presenting the rs $12979860-C C$ variant, the additional determination of rs 8099917 genotype had no value. IL28B rs12979860-CC remained significantly associated with SVR12 also in the multivariate analysis including the other baseline characteristics associated to SVR12 in the bivariate analysis (i.e., female gender, HCV genotype 1b, baseline viral load $<800,000 \mathrm{IU} / \mathrm{mL}$, advanced liver fibrosis and prior partial- or null-response to HCV therapy). Our study suggests that testing for the IL28B rs 12979860 genotype may still be useful in predicting response to triple therapy with boceprevir and telaprevir in naïve patients and treatmentexperienced patients other than partial and null-responders.
\end{abstract}

Keywords: Hepatitis C, HCV, Telaprevir, Boceprevir, IL28B, Predictive value

\section{Background}

In 2009, genome-wide association studies showed that single nucleotide polymorphisms (SNPs) located upstream the gene for interleukin-28 (IL28B) on chromosome 19 were strongly associated with sustained

\footnotetext{
*Correspondence: giorgiocalisti@gmail.com

${ }^{1}$ Department of Virology, Royal Free London NHS Foundation Trust, Pond Street, London NW5 4AP, UK

Full list of author information is available at the end of the article
}

virological response (SVR) to hepatitis $\mathrm{C}$ virus (HCV) treatment with pegylated interferon alpha PEG-IFN and ribavirin RBV (Ge et al. 2009; Suppiah et al. 2009; Tanaka et al. 2009). SNPs at rs12979860 and rs8099917 were identified: favourable outcome were seen with CC at rs12979860 compared to non-CC genotypes (CT or $\mathrm{TT}$ ), and unfavourable outcome were seen with GG or GT genotypes at rs8099917. The IL28B gene encodes for a protein named interferon-lambda-3, a type III interferon (IFN). The precise molecular mechanism

\section{Springer}


underlying the influence of IL28B polymorphism on response to PEG-IFN/RBV treatment for hepatitis C remains elusive. Based on the observation that patients carrying the unfavourable IL28B genotypes seem to have an inappropriately up-regulated intrahepatic expression of interferon-stimulated genes (ISGs), some authors have hypothesised that those with a favourable IL28B profile, having a lower intrahepatic ISGs expression, may be more sensitive to exogenous IFN and, thus, more likely to respond to treatment and to eradicate the infection (Honda et al. 2010; Urban et al. 2010).

Two years after the influence of IL28B SNPs was described, the first-generation protease inhibitors boceprevir and telaprevir were approved for treatment of genotype 1 chronic $\mathrm{HCV}$ infection in combination to PEG-IFN/RBV. These drugs substantially improved SVR rates for genotype $1 \mathrm{HCV}$ in both naïve and treatmentexperienced patients (Poordad et al. 2011; Jacobson et al. 2011; Bacon et al. 2011; Zeuzem et al. 2011; Pearlman 2012). The increased potency of these new directly acting agents (DAAs), has, however led some to question whether IL28B genotype testing still has any value (Jensen and Pol 2012). Retrospective analyses of phase-3 clinical trials of telaprevir and boceprevir have been conducted to evaluate the utility of IL28B genotype testing, but there are limited data outside clinical trials (Poordad et al. 2012; Pol et al. 2013; Jacobson et al. 2011).

This study assessed the value of two IL28B SNPs, rs12979860 and rs8099917, in predicting SVR to telaprevir or boceprevir triple therapy 12 weeks after treatment cessation (SVR12) in a single-centre cohort of previous $\mathrm{HCV}$ treatment-naïve and treatment-experienced patients treated outside of the clinical trial setting.

\section{Methods}

\section{Patient selection}

Patients with genotype 1 chronic $\mathrm{HCV}$ infection who received PEG-IFN/RBV and either telaprevir or boceprevir at The Royal Free London NHS Foundation Trust (UK) between June 2011 and December 2012 and had IL28B SNPs testing were included in the study. Prior to June 2012, patients started triple therapy through an expanded access programme (EAP) preceding approval of telaprevir and boceprevir by the National Institute for Health and Clinical Excellence (NICE). Patients coinfected with HIV or HBV and patients infected with $\mathrm{HCV}$ genotypes other than 1 were excluded. All patients were treated in accordance with the manufacturer's prescribing instructions.

Institutional review board approval was not required for this study as patients were treated with approved diagnostic and therapeutic procedures according to generally accepted standards of care and all data collected retrospectively were fully de-identified.

\section{Data collection}

Demographic, clinical and virological characteristics were collected retrospectively reviewing the clinical notes and the electronic laboratory reporting system.

Liver fibrosis was evaluated by liver biopsy performed within 24 months prior to treatment initiation in $45 \%$ of patients and by transient elastography in $25.8 \%$ of patients. In the remaining $29.2 \%$ of patients no liver biopsy or transient elastography was done because the diagnosis of liver cirrhosis was clear from routine clinical-radiological assessment. Fibrosis stage was categorised according to the METAVIR score. Where fibrosis was assessed by transient elastography the following cut-off values were used: $<7.1$ kilopascal $(\mathrm{kPa})$ for METAVIR F0-F1, 7.1-9.4 kPa for F2, 9.5-12.4 kPa for F3 and $>12.5 \mathrm{kPa}$ for F4 (Castera et al. 2005). All patients diagnosed with liver cirrhosis in the routine clinical-radiological assessment were classified as METAVIR F4.

As far as previous HCV treatment is concerned, patients were considered 'naïve' if they had no previous treatment with PEG-IFN/RBV, 'null-responders' if they failed previous $\mathrm{HCV}$ treatment with a viral load (VL) decrease of $<2 \log _{10} \mathrm{IU} / \mathrm{mL}$, 'partial responders' if they had a $>2 \log _{10}$ drop in VL but failed to clear the virus, 'virological breakthrough' if they achieved an undetectable VL initially but became viraemic again whilst on treatment, 'relapsers' if they achieved an undetectable HCV VL at the end of treatment (EOT) but relapsed during the subsequent 24-week follow-up and interruption due to side effects (SEs)' if discontinued prematurely treatment due to adverse reactions.

\section{Outcomes}

SVR12, defined as undetectable HCV VL at week 12 of follow-up after end of triple therapy treatment, was the primary outcome in our intention-to-treat analysis. The secondary outcome was a shortened course of triple therapy among patients considered eligible.

\section{Measurements}

HCV RNA was extracted from $1.5 \mathrm{~mL}$ of serum or plasma using the QiaSymphony platform (Qiagen, Crawley, UK) and HCV RNA VL was quantified using a validated inhouse real-time PCR (RT-PCR) assay that amplifies a portion of the highly conserved $5^{\prime}$ untranslated region (UTR) of HCV. The assay has a lower limit of quantification of $12 \mathrm{IU} / \mathrm{mL}$.

Human genomic DNA was extracted from plasma samples using the QiaSymphony mini DNA blood extraction kit. RT-PCR was performed for two single nucleotide 
polymorphisms (SNPs) within the IL28B locus (C or T for rs12979860 and G or T for rs8099917) using TaqMan allelic discrimination assay, as previously described.

\section{Statistical analysis}

Firstly, we compared the distribution of baseline characteristics and the differences in SVR12 rates in patients receiving triple therapy through the EAP and patients treated after telaprevir and boceprevir were introduced in the UK market. Since no significant difference in SVR12 rates were observed in the two groups, we proceeded to analyse the study cohort as a whole and we evaluated the significance of associations between the study population's baseline characteristics, including the different IL28B SNPs, and SVR12 rates to triple therapy. Patients naïve to previous $\mathrm{HCV}$ treatment were compared to the rest of the study cohort (all treatment-experienced patients). Each treatment-experienced subgroup (i.e., previous interruption due to SEs, viral breakthrough, relapsers, partial-responders and null-responders) was compared separately to naïve patients. Because no significant differences in outcomes between boceprevir and telaprevir groups were observed, all patients were analysed as one cohort. Two-tailed Pearson's Chi squared, Fisher's exact and Mann-Whitney U tests were used in the bivariate analyses. Hardy-Weinberg equilibrium of observed versus predicted IL28B genotype frequencies and the degree of linkage disequilibrium between the two SNPs were assessed by two-tailed Pearson's Chi squared test. P values of $<0.05$ were considered to be statistically significant.

All factors significantly associated with SVR12 in the bivariate analyses were included in the multivariate logistic regression analyses. For the multivariate logistic regression analysis, we dichotomised previous $\mathrm{HCV}$ treatment categories in two groups:

1. One group including naïve patients, patients who interrupted treatment due to SEs and prior virological breakthrough and relapsers;

2. another group including prior partial and null responders.

We also dichotomised HCV genotype categories in one group including only genotype $1 \mathrm{~b}$ and the other group comprising genotype 1a and all patients with genotype 1 where subtyping was not done.

Finally, we assessed by unadjusted and adjusted logistic regression analysis the associations between the rs12979860-CC and the rs8099917-TT genotypes and SVR12 in the two previous HCV treatment sub-groups. We also calculated sensitivity, specificity, positive predictive value (PPV) and negative predictive value (NPV) of the two favourable IL28B variants in relation to SVR12.
Data analysis was performed using Stata v12 (StataCorp LP, College Station, TX, USA).

\section{Results}

Overall, 105 patients with HCV genotype 1 infection started triple therapy with either telaprevir or boceprevir during the study period. Around half (50.5\%) of the patients in our cohort, started triple therapy through the EAP. Differences in the baseline characteristics between patients enrolled in the EAP and patients selected for triple therapy following formal launch of telaprevir and boceprevir in the UK market are summarised in Table 1. Patients treated through the EAP were older $(\mathrm{p}=0.010)$, more likely to be treatment-experienced $(\mathrm{p}=0.001)$ and null-responders $(\mathrm{p}=0.038)$ to previous HCV therapy. A smaller proportion of patients treated through the EAP achieved SVR12 compared to patients treated outside of the EAP (60.4 vs $71.2 \%)$ but this difference was not statistically significant $(\mathrm{p}=0.245)$.

Baseline characteristics, including distribution of the two IL28B SNP genotypes, and their associations with SVR 12 for the whole cohort of 105 patients are shown in Table 2. Most patients (72.4\%). in the study cohort were treatment-experienced and $29.7 \%$ were partial or null responder to previous $\mathrm{HCV}$ therapy. Almost half (47.6\%) of all patients had advanced fibrosis (METAVIR F3 or F4). Whilst the genotypic frequencies of the IL28B SNP at rs8099917 were in Hardy-Weinberg equilibrium, the genotypic frequencies of rs12979860 were not $(p=0.007)$, with more CT genotypes and less CC genotypes observed than expected. Strong linkage disequilibrium between IL28B s12979860 and rs8099917 was observed ( $\mathrm{p}<0.001)$. All 23 patients who had genotype $\mathrm{CC}$ at rs12979860 had also genotype TT at rs8099917, whereas only $51.1 \%(23 / 45)$ of patients with genotype TT at rs8099917 had genotype CC at rs12979860, the remaining $48.9 \%(22 / 45)$ being genotype CT. The proportion of genotype CC at rs12979860 was lower among partial- and null-responder to previous $\mathrm{HCV}$ treatment compared to the rest of the cohort (9.7 vs $27 \%, \mathrm{p}=0.050$ ) (Figure 1).

The overall SVR12 rate in our mixed cohort of treatment-naïve and treatment-experienced patients was $65.7 \%$. Of the 36 patients who failed to achieve SVR12 to triple therapy, 9 patients ( $8.6 \%$ of the whole cohort) stopped because of side effects. Treatment was stopped due to side effects in 1 out of 17 patients started on boceprevir and 8 out of 88 patients started on telaprevir $(\mathrm{p}=1.000)$. Side effects leading to treatment interruption were severe dermatitis in 2 patients, mental health problems in 2 patients, gastrointestinal intolerance in 2 patients, neutropaenic sepsis in 1 patient, severe anaemia and fatigue in 1 patient and IFN-associated retinopathy 
Table 1 Baseline characteristics and SVR12 rates in patients started on treatment through the EAP and patients started on treatment outside the EAP

\begin{tabular}{|c|c|c|c|c|}
\hline Variable & $\begin{array}{l}\text { All patients } \\
(n=105)\end{array}$ & $\begin{array}{l}\text { Treated through the } \\
\text { EAP }(n=53)\end{array}$ & $\begin{array}{l}\text { Treated outside the } \\
\text { EAP }(n=52)\end{array}$ & $P$ value \\
\hline Gender, female $(n, \%)$ & $31(29.5)$ & $15(28.3)$ & $16(30.8)$ & 0.782 \\
\hline Age, years (median, IQR) & $52(10)$ & $53(9)$ & $50(7)$ & 0.010 \\
\hline Age, $<52$ years $(n, \%)$ & $46(43.8)$ & $18(34.0)$ & $28(53.8)$ & 0.04 \\
\hline \multicolumn{5}{|l|}{ Ethnicity } \\
\hline White/Caucasian $(n, \%)$ & $86(81.9)$ & $45(84.9)$ & $41(78.8)$ & 0.298 \\
\hline $\operatorname{Black}(n, \%)$ & $6(5.7)$ & $3(90.6)$ & $3(5.8)$ & 0.981 \\
\hline Other $(n, \%)$ & $13(12.3)$ & $5(9.5)$ & $8(15.4)$ & 0.355 \\
\hline \multicolumn{5}{|l|}{ Liver fibrosis } \\
\hline Non-advanced, i.e. METAVIR F0-F2 ( $n, \%)$ & $55(52.4)$ & $24(45.3)$ & $31(59.6)$ & 0.141 \\
\hline Advanced, i.e. METAVIR F3 or F4 $(n, \%)$ & $50(47.6)$ & $29(54.7)$ & $21(40.4)$ & \\
\hline \multicolumn{5}{|l|}{ Previous HCV treatment } \\
\hline Naïve & $29(27.6)$ & $6(11.3)$ & $23(44.2)$ & 0.001 \\
\hline Interruption due to side effects & $5(4.8)$ & $2(3.8)$ & $3(5.8)$ & 0.631 \\
\hline Viral breakthrough & $7(6.7)$ & $6(11.3)$ & $1(1.9)$ & 0.113 \\
\hline Relapser & $33(31.4)$ & $18(34.0)$ & $15(28.8)$ & 0.572 \\
\hline Partial responder & $8(7.6)$ & $5(9.4)$ & $3(5.8)$ & 0.479 \\
\hline Null responder & $23(21.9)$ & $16(30.2)$ & $7(13.5)$ & 0.038 \\
\hline \multicolumn{5}{|l|}{ HCV protease inhibitor } \\
\hline Boceprevir $(n, \%)$ & $17(16.2)$ & $11(20.7)$ & $6(11.6)$ & 0.200 \\
\hline Telaprevir ( $n, \%)$ & $88(83.8)$ & $42(79.3)$ & $46(88.4)$ & \\
\hline \multicolumn{5}{|l|}{ HCV genotype } \\
\hline $1 a$ & $45(42.9)$ & $24(45.3)$ & $21(40.4)$ & 0.281 \\
\hline $1 b$ & $43(40.9)$ & $18(34.0)$ & $25(48.1)$ & \\
\hline 1 non-subtyped & $17(16.2)$ & $11(20.7)$ & $6(11.5)$ & 0.290 \\
\hline HCV viral load, IU/mL (median, IQR) & $1,833,451(3,459,687)$ & $1,893,740(3,480,802)$ & $1,588,705(3,024,102)$ & 0.423 \\
\hline HCV viral load, $<800,000 \mathrm{IU} / \mathrm{mL}(n, \%)$ & $30(28.5)$ & $14(26.4)$ & $16(30.8)$ & 0.621 \\
\hline \multicolumn{5}{|l|}{ IL28B rs12979860 genotype } \\
\hline$C C(n, \%)$ & $23(21.9)$ & $8(15.1)$ & $15(28.8)$ & 0.088 \\
\hline $\mathrm{CT}(n, \%)$ & $67(63.8)$ & $37(69.8)$ & $30(57.7)$ & 0.196 \\
\hline $\mathrm{TT}(n, \%)$ & $15(14.3)$ & $8(15.1)$ & $7(13.5)$ & 0.811 \\
\hline \multicolumn{5}{|l|}{ IL28B rs8099917 genotype } \\
\hline $\mathrm{TT}(n, \%)$ & $45(42.8)$ & $22(41.5)$ & $23(44.2)$ & 0.778 \\
\hline $\mathrm{GT}(n, \%)$ & $51(48.6)$ & $28(52.8)$ & $23(44.2)$ & 0.378 \\
\hline $\mathrm{GG}(n, \%)$ & $9(8.6)$ & $3(5.7)$ & $6(11.6)$ & 0.319 \\
\hline SVR12 to triple therapy & $69(65.7)$ & $32(60.4)$ & $37(71.2)$ & 0.245 \\
\hline
\end{tabular}

in another patient. Overall, $42.9 \%$ of patients (45/105) required either PEG-IFN or RBV dose reductions, the most common reasons being anaemia (25 patients), thrombocytopenia (11 patients) and neutropaenia (5 patients).

No significant differences in SVR12 rates were observed between patients who had their PEG-IFN or RBV dose modified compared to the rest of the study cohort $(60.0$ vs $70.0 \%, \mathrm{p}=0.389$ ).

Among the baseline characteristics examined, female gender $(\mathrm{p}=0.037)$, a history of relapse following previous $\mathrm{HCV}$ treatment $(\mathrm{p}=0.020), \mathrm{HCV}$ genotype
$1 b(p=0.001)$, a HCV VL lower than $800,000 \mathrm{IU} / \mathrm{mL}$ $(\mathrm{p}=0.016)$ and IL28B genotype CC at rs12979860 $(\mathrm{p}=0.015)$ were all significantly associated with SVR12, whereas advanced liver fibrosis $(\mathrm{p}=0.046)$, a history of prior null-response to PEG-IFN/RBV ( $\mathrm{p}=0.008$ ) or the status of prior partial or null-responder to previous $\mathrm{HCV}$ therapy $(\mathrm{p}=0.001)$ were all significantly associated to a non-response to triple therapy (Table 2). In our study, there was no added value in combining IL28B genotype CC at rs12979860 and genotype TT at rs8099917 testing compared to genotype CC at rs12979860 testing alone. 
Table 2 Baseline characteristics associated with SVR12 to triple therapy

\begin{tabular}{|c|c|c|c|c|}
\hline Baseline characteristics & $\begin{array}{l}\text { All patients } \\
(n=105)\end{array}$ & $\begin{array}{l}\text { Patients who achieved } \\
\text { SVR12 to triple } \\
\text { therapy }(n=69)\end{array}$ & $\begin{array}{l}\text { Patients who did } \\
\text { not achieve SVR12 } \\
\text { to triple therapy }(n=36)\end{array}$ & P value \\
\hline Gender, female $(n, \%)$ & $31(29.5)$ & $25(36.2)$ & $6(16.6)$ & 0.037 \\
\hline Age, years (median, IQR) & $52(10)$ & $52(16)$ & $53(8)$ & 0.151 \\
\hline Age, $<52$ years $(n, \%)$ & $46(43.8)$ & $33(47.8)$ & $13(36.1)$ & 0.251 \\
\hline \multicolumn{5}{|l|}{ Ethnicity } \\
\hline White/Caucasian ( $n, \%)$ & $86(81.9)$ & $58(84.1)$ & $28(77.8)$ & 0.550 \\
\hline $\operatorname{Black}(n, \%)$ & $6(5.7)$ & $2(2.9)$ & $4(11.1)$ & 0.085 \\
\hline Other $(n, \%)$ & $13(12.3)$ & $9(13)$ & $4(11.1)$ & 0.775 \\
\hline \multicolumn{5}{|l|}{ Liver fibrosis } \\
\hline Non-advanced, i.e. METAVIR F0-F2 ( $n, \%)$ & $55(52.4)$ & $41(59.4)$ & $14(38.9)$ & 0.046 \\
\hline Advanced, i.e. METAVIR F3 or F4 $(n, \%)$ & $50(47.6)$ & $28(40.6)$ & $22(61.1)$ & \\
\hline \multicolumn{5}{|l|}{ Previous HCV treatment } \\
\hline Naïve & $29(27.6)$ & $22(31.9)$ & $7(19.4)$ & 0.340 \\
\hline Interruption due to side effects & $5(4.8)$ & $3(4.3)$ & $4(11.1)$ & 0.783 \\
\hline Viral breakthrough & $7(6.7)$ & $3(4.3)$ & $4(11.1)$ & 0.393 \\
\hline Relapser & $33(31.4)$ & $28(40.6)$ & $5(13.9)$ & 0.020 \\
\hline Partial responder & $8(7.6)$ & $4(5.8)$ & $4(11.1)$ & 0.587 \\
\hline Null responder & $23(21.9)$ & $9(13)$ & $14(38.9)$ & 0.008 \\
\hline $\begin{array}{l}\text { Naïve, interruption due to side effects, viral } \\
\text { breakthrough and relapsers }(n, \%)\end{array}$ & $74(70.5)$ & $56(81.2)$ & $18(50.0)$ & 0.001 \\
\hline Partial and null responders $(n, \%)$ & $31(29.5)$ & $13(18.8)$ & $18(50.0)$ & \\
\hline \multicolumn{5}{|l|}{ HCV protease inhibitor } \\
\hline Boceprevir $(n, \%)$ & $17(16.2)$ & $13(18.8)$ & $4(11.1)$ & 0.307 \\
\hline Telaprevir $(n, \%)$ & $88(83.8)$ & $56(81.2)$ & $32(88.9)$ & \\
\hline \multicolumn{5}{|l|}{ HCV genotype } \\
\hline $1 a$ & $45(42.9)$ & $21(30.4)$ & $24(66.7)$ & 0.001 \\
\hline $1 b$ & $43(40.9)$ & $35(50.7)$ & $8(22.2)$ & \\
\hline 1 non-subtyped & $17(16.2)$ & $13(18.8)$ & $4(11.1)$ & 0.307 \\
\hline $1 \mathrm{a}$ and 1 non-subtyped $(n, \%)$ & $62(59.1)$ & $34(49.3)$ & $28(77.8)$ & 0.005 \\
\hline $1 \mathrm{~b}(n, \%)$ & $43(40.9)$ & $35(50.7)$ & $8(22.2)$ & \\
\hline HCV viral load, IU/mL (median, IQR) & $1,833,451(3,459,687)$ & $1,417,630(2,505,928)$ & $2,115,100(4,038,313)$ & 0.005 \\
\hline HCV viral load, $<800,000 \mathrm{IU} / \mathrm{mL}(n, \%)$ & $30(28.5)$ & $25(36.2)$ & $5(13.9)$ & 0.016 \\
\hline \multicolumn{5}{|l|}{ IL28B rs12979860 genotype } \\
\hline $\operatorname{CC}(n, \%)$ & $23(21.9)$ & $20(29)$ & $3(8.3)$ & 0.015 \\
\hline $\mathrm{CT}(n, \%)$ & $67(63.8)$ & $42(60.9)$ & $25(69.4)$ & 0.385 \\
\hline $\mathrm{TT}(n, \%)$ & $15(14.3)$ & $7(10.1)$ & $8(22.2)$ & 0.093 \\
\hline \multicolumn{5}{|l|}{ IL28B rs8099917 genotype } \\
\hline $\mathrm{TT}(n, \%)$ & $45(42.8)$ & $34(49.3)$ & $11(30.5)$ & 0.066 \\
\hline $\mathrm{GT}(n, \%)$ & $51(48.6)$ & $31(44.9)$ & $20(55.6)$ & 0.301 \\
\hline $\mathrm{GG}(n, \%)$ & $9(8.6)$ & $4(5.8)$ & $5(13.9)$ & 0.160 \\
\hline \multicolumn{5}{|l|}{ Combinations of IL28B SNPS } \\
\hline rs12979860-CC and rs8099917-TT (n, \%) & $23(21.9)$ & $20(29)$ & $3(8.3)$ & 0.015 \\
\hline rs12979860-CC and rs8099917-GT ( $n, \%)$ & 0 & 0 & 0 & / \\
\hline rs12979860-CC and rs8099917-GG $(n, \%)$ & 0 & 0 & 0 & / \\
\hline rs12979860-CT and rs8099917-TT (n, \%) & $22(20.9)$ & $14(20.3)$ & $8(22.2)$ & 0.514 \\
\hline rs12979860-CT and rs8099917-GT $(n, \%)$ & $45(42.9)$ & $28(40.6)$ & $17(47.2)$ & 0.817 \\
\hline rs12979860-CT and rs8099917-GG $(n, \%)$ & 0 & 0 & 0 & / \\
\hline rs12979860-TT and rs8099917-TT $(n, \%)$ & 0 & 0 & 0 & / \\
\hline rs12979860-TT and rs8099917-GT (n, \%) & $6(5.7)$ & $3(4.3)$ & $3(8.3)$ & 0.404 \\
\hline rs12979860-TT and rs8099917-GG $(n, \%)$ & $9(8.6)$ & $4(5.8)$ & $5(13.9)$ & 0.160 \\
\hline
\end{tabular}


Naive, interruption due to side effects, viral breakthrough and relapsers to previous HCV therapy

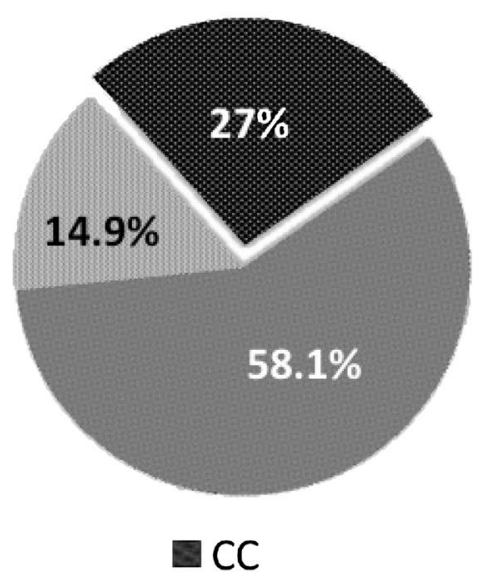

\section{Partial responder and null responder to previous HCV therapy}

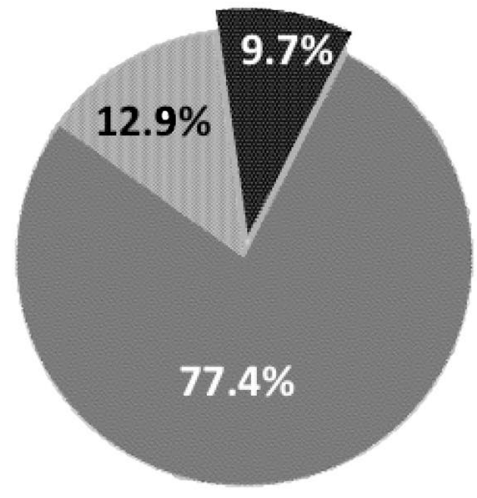

Figure 1 Distribution of the different IL28B rs12979860 variants according to prior hepatitis C therapy group.

On multivariate logistic regression analysis, $\mathrm{HCV}$ genotype $1 \mathrm{~b}$ (OR 3.4, 95\% CI 1.20-9.51) and IL28B genotype CC at rs12979860 (OR 7.4, 95\% CI 1.70-32.08) remained significantly associated with SVR12 to triple therapy, whereas advanced liver fibrosis (OR 0.3, 95\% CI $0.12-$ 0.89 ) and a history of previous partial or null-response to PEG-IFN/RBV treatment (OR 0.3, 95\% CI 0.12-0.94) remained significantly associated with failure to achieve SVR12 to triple therapy (Table 3).

In the unadjusted logistic regression subgroup analysis according to previous HCV treatment history, both IL28B 12979860-CC genotype and rs8099917-TT genotype were significantly associated with SVR12 in the group including patients naïve, patients who interrupted treatment due to SEs, patients with a history of viral breakthrough or relapse (OR 7.3 and 4.34, respectively) (Table 4). No significant association was found between any of the SNPs and SVR12 in the subgroup including partial and null responders to previous HCV therapy.

In the adjusted regression analysis including both favourable SNPs, IL28B 12979860-CC maintained is significant association with SVR12 in the whole cohort and a trend towards significance was observed also in the subgroup of patients naïve, interruption due to SEs, virological breakthrough and relapsers, whereas the association between rs8099917-TT and SVR12 disappeared in all treatment groups (Table 4).

PPV of IL28B genotype CC at rs12979860 in relation to the likelihood of achieving SVR12 was 87\% (95\% CI 65.396.6\%) in the whole study cohort, 95\% (95\% CI 73.1$99.7 \%$ ) in the group including patients naïe, patients who interrupted treatment due to SEs and patients with a history of viral breakthrough during treatment or relapse after EOT. PPV of genotype rs8099917-TT in relation to SVR12 was $75.6 \%$ (95\% CI 60.1-86.6) in the whole study cohort and 88.6\% (95\% CI 72.3-96.3) in the group including patients naïve, patients who interrupted treatment due to side effects and patients with a history of viral breakthrough during treatment or relapse after EOT.

Five out of 7 and 25 out of 34 patients considered eligible at baseline received a shortened course of therapy with boceprevir and telaprevir, respectively. Overall duration of triple therapy could be shortened in $73.2 \%$ of patients. None of the baseline characteristics, including IL28B genotype CC at rs12979860, was significantly associated with the likelihood of receiving a shortened course of triple therapy.

\section{Conclusions}

There is a lack of published data on the utility of IL28B genotyping in predicting SVR to triple therapy with telaprevir and boceprevir. In our cohort, IL28B genotype CC at rs12979860 and genotype TT at rs8099917 were significantly associated with SVR12 and predicted successful virological cure following triple therapy in the subgroup of patients comprising both patients naivve to previous therapy and patients who failed prior treatment but showed the ability to respond to PEG-IFN/RBV (i.e., previous virological breakthrough and relapsers).

Poordad et al. (2012) reviewed the factors associated with SVR in the boceprevir studies SPRINT-2 on treatment-naïve patients and RESPOND-2, on 
Table 3 Multivariate logistic regression analysis of baseline characteristics significantly associated with SVR12 to triple therapy in the bivariate analysis

\begin{tabular}{llll}
\hline Variable & \multicolumn{3}{l}{$\begin{array}{l}\text { Association with SVR12 } \\
\text { to triple therapy }\end{array}$} \\
\cline { 2 - 5 } & OR & $\mathbf{9 5 \%}$ Cl & P value \\
\hline Gender female & 1.4 & $0.42-4.50$ & 0.594 \\
Advanced liver fibrosis (METAVIR F3 or F4) & 0.3 & $0.12-0.89$ & 0.029 \\
Partial or null-responders to previous HCV & 0.3 & $0.12-0.94$ & 0.039 \\
$\quad$ therapy & & & \\
HCV genotype 1b & 3.4 & $1.20-9.51$ & 0.021 \\
Baseline HCV viral load $<800,000 ~ I U / m L$ & 3.0 & $0.89-10.22$ & 0.076 \\
IL28B rs12979860-CC & 7.4 & $1.70-32.08$ & 0.007 \\
\hline
\end{tabular}

$O R$ odds ratio, $\mathrm{Cl}$ confidence intervals.

treatment-experienced patients. The CC genotype at rs12979860 was independently associated with SVR in SPRINT-2 but not in RESPOND-2. In both studies, the rs12979860-CC genotype was associated strongly with a good response to interferon at week $4\left(>1 \log _{10} \mathrm{VL}\right.$ decline after the lead-in phase) and could therefore be used to identify patients eligible for shorter treatment duration. This association, however, disappeared in the multivariate regression analysis. In the ADVANCE study, which evaluated telaprevir for naïve patients,
rs12979860-CC genotype patients were more likely to be eligible for shortened duration of treatment and achieve an eRVR (Jacobson et al. 2011). Finally, in treatmentfailure patients treated with telaprevir-based therapy (REALIZE study), IL28B did not significantly affect SVR in the multivariate analysis (Pol et al. 2013).

In our study, the predictive value of both IL28B polymorphisms in relation to the likelihood of achieving SVR12 to triple therapy was seen only in the sub-group including the patients with favourable prior HCV treatment history (i.e., naïve, patients who interrupted treatment due to SE, patients with a history of virological breakthrough during treatment or relapse after EOT). These findings are comparable with the results of the clinical trials, which reported a significant effect of IL28B genotype only in treatment naïve individuals (Poordad et al. 2012; Jacobson et al. 2011).

In this study, rs12979860-CC was a stronger predictor of SVR12 than rs8099917-TT. In patients presenting the rs12979860-CC, the additional determination of rs8099917 genotype had no value. When the two variants were compared directly by multivariate logistic regression analysis, only rs 12979860-CC remained significantly associated to treatment success. Our results are in line with several larger studies conducted in patients treated with the combination PEG-IFN/RBV (Bochud et al. 2011; Fischer et al. 2012).

Table 4 Unadjusted and adjusted logistic regression analysis of the associations between IL28B rs12979860-CC and rs8099917-TT and SVR12 to triple therapy according to previous HCV treatment group

\begin{tabular}{lccc}
\hline & $\begin{array}{l}\text { All patients } \\
\text { (105 patients) }\end{array}$ & $\begin{array}{l}\text { Naïve, interruption due } \\
\text { to SEs, viral breakthrough } \\
\text { and relapsers (74 patients) }\end{array}$ & $\begin{array}{c}\text { Partial and null } \\
\text { reponders } \\
\text { (31 patients) }\end{array}$ \\
\hline SVR12 (95\% Cl) & $65.7 \%(56.6-74.8)$ & $75.7 \%(65.9-85.5)$ & $41.9 \%(24.5-59.3)$ \\
IL28B rs12979860-CC & & $27 \%(16.9-37.1)$ & $9.7 \%(0.0-20.1)$ \\
Frequency (95\% Cl) & $21.9 \%(14.0-29.8)$ & $8.7(1.08-70.67)$ & $0.67(0.05-8.24)$ \\
Unadjusted OR (95\% Cl) & $4.4(1.23-16.33)$ & $7.3(0.88-61.18)$ & $0.59(0.47-7.43)$ \\
Adjusted OR (95\% Cl) & $3.97(1.07-14.72)$ & $33.9 \%(22.2-47.9)$ & $7.7 \%(0.4-37.9)$ \\
Sensitivity (95\% Cl) & $29.0 \%(19.0-41.3)$ & $94.4 \%(70.6-99.7)$ & $88.9 \%(63.9-98.1)$ \\
Specificity (95\% Cl) & $91.7 \%(76.4-97.8)$ & $95.0 \%(73.1-99.7)$ & $33.3 \%(1.8-87.5)$ \\
PPV (95\% Cl) & $87.0 \%(65.3-96.6)$ & $31.5 \%(19.9-45.7)$ & $57.1 \%(37.4-75.0)$ \\
NPV (95\% Cl) & $40.2 \%(29.7-51.7)$ & & $32.3 \%(15.8-48.8)$ \\
IL28B rs8099917-TT & & $47.3 \%(35.9-58.7)$ & $0.47(0.10-2.34)$ \\
Frequency (95\% Cl) & $42.8 \%(33.4-52.4)$ & $4.3(1.27-14.84)$ & $0.39(0.04-4.35)$ \\
Unadjusted OR (95\% Cl) & $2.20(0.94-5.17)$ & $0.46(0.12-1.82)$ & $23.1 \%(6.2-54.0)$ \\
Adjusted OR (95\% Cl) & $0.52(0.17-14.72)$ & $55.4 \%(41.6-68.4)$ & $61.1 \%(36.1-81.7)$ \\
Sensitivity (95\% Cl) & $49.3 \%(37.1-61.5)$ & $77.8 \%(51.9-92.6)$ & $30.0 \%(8.1-64.6)$ \\
Specificity (95\% Cl) & $69.4 \%(51.7-83.1)$ & $88.6 \%(72.3-96.3)$ & $52.4 \%(30.3-73.6)$ \\
PPV (95\% Cl) & $75.6 \%(60.1-86.6)$ & $35.9 \%(21.7-52.8)$ & \\
NPV (95\% Cl) & $41.7 \%(29.3-55.1)$ & & \\
\hline
\end{tabular}

Sensitivity, specificity, PPV, NPV of the two favourable IL28B variants in relation to SVR12.

$O R$ odds ratio, $\mathrm{Cl}$ confidence intervals, $P P V$ positive predictive value, $N P V$ negative predictive value. 
Because around half of our study population was started on treatment through the EAP, the results of this study may not be entirely generalizable to the "realworld". Although patients enrolled through the EAP may have been more difficult to cure because older and more likely to be treatment-experienced and null-responder to previous HCV therapy, we cannot exclude a selection bias whereby the treating physicians may have preferentially enrolled in the EAP the most motivated patients. This could explain why, even in this subgroup of patients where over $90 \%$ of subjects were treatment-experienced and the majority had advanced liver fibrosis, a SVR12 rate of $60.4 \%$ was observed. This is higher than the cure rate reported by the two largest "real-world" case series of patients treated with telaprevir- or boceprevir-based triple therapy published to date: Ioannou et al. (2014) analysis of the Veterans Administration (VA) healthcare system cohort and Price et al. (2014) analysis of Northern California Kaiser Permanente (KPNC) cohort. Since compliance was not consistently noted for all patients and throughout the study period, we are unable to prove the link between this hypothetical selection bias and the increased SVR12 rate. Other differences in cohort composition could explain our greater SVR12 rate. The VA cohort had a greater proportion of men ( $96 \mathrm{vs} 70.5 \%$ ) and a smaller proportion of patients infected with HCV genotype $1 \mathrm{~b}$ ( 21.3 vs $48.9 \%$, considering only patients who had genotype 1 subtyping performed) (Ioannou et al. 2014). In the KPNC cohort HCV genotype $1 \mathrm{~b}$ was less frequent than in our study population (33.7 vs $48.9 \%$, considering only patients who had genotype 1 subtyping performed) and the proportion of black individuals was greater (15 vs 5.7\%) (Price et al. 2014). IL28B genotype composition was not reported in the KPNC study, however, because the CC profile at rs12979860 is less common among black patients, it is possible that a smaller proportion of patients had the most favourable profile (Clark et al. 2011).

In summary, our study suggests that, outside the clinical trials setting, IL28B testing genotype CC at rs12979860 remains predictive of SVR12 to telaprevirand boceprevir-based triple therapy. Similar to the retrospective analyses of phase- 3 clinical trials, the predictive value of rs12979860-CC was observed only in patients in the most favourable previous $\mathrm{HCV}$ treatment categories, such as naïve patients, subjects that interrupted PEG-IFN/RBV therapy due to adverse events, prior viral breakthrough and relapsers. More efficacious and bettertolerated DAAs are now available. Although preliminary data suggest that patients with a favourable IL28B genotype seem to have slightly better chances of cure even with some interferon-free combinations, the influence of IL28B is likely to fade away when SVR rates approaches
$>90 \%$ in all patients (Holmes et al. 2012). In countries where this new wave of DAAs is already replacing telaprevir and boceprevir, testing for IL28B may be considered futile. However, in those settings where the use of the newer DAAs will be restrained for some time due to limited economic resources, testing for IL28B genotype may still be used, in addition to other baseline predictors, to identify patients that can be successfully treated with the telaprevir- and boceprevir-based treatment regimens.

\section{Authors' contributions}

GC and TH conceived the study. MJ, GD and WMR provided and cared for the study patients. MJM, AM and WL participated in the molecular virological and genetic studies. GC, AT and MJM participated in data acquisition. GC performed the data analysis and interpretation. GC and TH wrote the manuscript and all other authors contributed to its final version. All authors read and approved the final manuscript.

\section{Author details}

${ }^{1}$ Department of Virology, Royal Free London NHS Foundation Trust, Pond Street, London NW5 4AP, UK. ${ }^{2}$ The UCL Institute for Liver and Digestive Health/ Royal Free London NHS Foundation Trust Viral Hepatitis Service, London, UK.

\section{Acknowledgements}

The authors would like to thank the nursing staff at the Viral Hepatitis Services at Royal Free Hospital for their invaluable help in supplying relevant clinical data. The authors would also like to thank the technical staff at the Virology department at Royal Free Hospital for carrying out routine diagnostic tests.

\section{Compliance with ethical guidelines}

\section{Competing interests}

MJ served as a member of advisory boards and speakers' bureaus for Gilead and Janssen. GD served as a member of advisory boards and received research funding from Merck, Janssen, GlaxoSmithKline, Abbvie and Gilead. WMR is an investigator and speaker for Janssen and sits on advisory boards for Janssen and Merck. GC, AT, AMC, WL have no potential competing interests to declare.

Received: 16 February 2015 Accepted: 3 July 2015

Published online: 16 July 2015

\section{References}

Bacon BR, Gordon SC, Lawitz E, Marcellin P, Vierling JM, Zeuzem S et al (2011) Boceprevir for previously treated chronic HCV genotype 1 infection. N Engl J Med 364(13):1207-1217. doi:10.1056/NEJMoa1009482

Bochud PY, Bibert S, Negro F, Haagmans B, Soulier A, Ferrari C et al (2011) IL28B polymorphisms predict reduction of HCV RNA from the first day of therapy in chronic hepatitis C. J Hepatol 55(5):980-988. doi:10.1016/j. jhep.2011.01.050

Castera L, Vergniol J, Foucher J, Le Bail B, Chanteloup E, Haaser M et al (2005) Prospective comparison of transient elastography, Fibrotest, APRI, and liver biopsy for the assessment of fibrosis in chronic hepatitis C. Gastroenterology 128(2):343-350

Clark PJ, Thompson AJ, McHutchison JG (2011) IL28B genomic-based treatment paradigms for patients with chronic hepatitis $C$ infection: the future of personalized HCV therapies. Am J Gastroenterol 106(1):38-45. doi:10.1038/ajg.2010.370

Fischer J, Bohm S, Scholz M, Muller T, Witt H, George J et al (2012) Combined effects of different interleukin-28B gene variants on the outcome of dual combination therapy in chronic hepatitis C virus type 1 infection. Hepatology 55(6):1700-1710. doi:10.1002/hep.25582

Ge D, Fellay J, Thompson AJ, Simon JS, Shianna KV, Urban TJ et al (2009) Genetic variation in IL28B predicts hepatitis C treatment-induced viral clearance. Nature 461(7262):399-401. doi:10.1038/nature08309 
Holmes JA, Desmond PV, Thompson AJ (2012) Does IL28B genotyping still have a role in the era of direct-acting antiviral therapy for chronic hepatitis C infection? J Viral Hepatitis 19(10):677-684. doi:10.1111/jvh.12003 Honda M, Sakai A, Yamashita T, Nakamoto Y, Mizukoshi E, Sakai Y et al (2010) Hepatic ISG expression is associated with genetic variation in interleukin $28 \mathrm{~B}$ and the outcome of IFN therapy for chronic hepatitis C. Gastroenterology 139(2):499-509. doi:10.1053/j.gastro.2010.04.049

loannou GN, Beste LA, Green PK (2014) Similar effectiveness of boceprevir and telaprevir treatment regimens for hepatitis $C$ virus infection on the basis of a nationwide study of veterans. Clin Gastroenterol Hepatol 12(8):13711380. doi:10.1016/j.cgh.2013.12.011

Jacobson IM, McHutchison JG, Dusheiko G, Di Bisceglie AM, Reddy KR, Bzowej NH et al (2011a) Telaprevir for previously untreated chronic hepatitis C virus infection. N Engl J Med 364(25):2405-2416. doi:10.1056/ NEJMoa1012912

Jacobson IM, Catlett I, Marcellin P, Bzowej NH, Muir AJ, Adda N et al (2011) Telaprevir substantially improved SVR rates accross all IL28B genotypes in the ADVANCE trial. J Hepatol 54:Abstract 1369

Jensen DM, Pol S (2012) IL28B genetic polymorphism testing in the era of direct acting antivirals therapy for chronic hepatitis C: ten years too late? Liver Int Off J Int Assoc Study Liver 32(Suppl 1):74-78. doi:10.1111/j.1478-3231.2011.02712.x

Pearlman BL (2012) Protease inhibitors for the treatment of chronic hepatitis C genotype-1 infection: the new standard of care. Lancet Infect Dis 12(9):717-728. doi:10.1016/S1473-3099(12)70060-9

Pol S, Aerssens J, Zeuzem S, Andreone P, Lawitz EJ, Roberts S et al (2013) Limited impact of IL28B genotype on response rates in telaprevir-treated patients with prior treatment failure. J Hepatol 58(5):883-889. doi:10.1016/j.jhep.2012.12.023

Poordad F, McCone J Jr, Bacon BR, Bruno S, Manns MP, Sulkowski MS et al (2011) Boceprevir for untreated chronic HCV genotype 1 infection. N Engl J Med 364(13):1195-1206. doi:10.1056/NEJMoa1010494

Poordad F, Bronowicki JP, Gordon SC, Zeuzem S, Jacobson IM, Sulkowski MS et al (2012) Factors that predict response of patients with hepatitis C virus infection to boceprevir. Gastroenterology 143(3):608-618.e1-5. doi:10.1053/j.gastro.2012.05.011

Price JC, Murphy RC, Shvachko VA, Pauly MP, Manos MM (2014) Effectiveness of telaprevir and boceprevir triple therapy for patients with hepatitis $C$ virus infection in a large integrated care setting. Dig Dis Sci 59(12):3043-3052. doi:10.1007/s10620-014-3294-0

Suppiah V, Moldovan M, Ahlenstiel G, Berg T, Weltman M, Abate ML et al (2009) $\mathrm{IL} 28 \mathrm{~B}$ is associated with response to chronic hepatitis $\mathrm{C}$ interferon-alpha and ribavirin therapy. Nat Genet 41(10):1100-1104. doi:10.1038/ng.447

Tanaka Y, Nishida N, Sugiyama M, Kurosaki M, Matsuura K, Sakamoto N et al (2009) Genome-wide association of IL28B with response to pegylated interferon-alpha and ribavirin therapy for chronic hepatitis C. Nat Genet 41(10):1105-1109. doi:10.1038/ng.449

Urban TJ, Thompson AJ, Bradrick SS, Fellay J, Schuppan D, Cronin KD et al (2010) IL28B genotype is associated with differential expression of intrahepatic interferon-stimulated genes in patients with chronic hepatitis $C$ Hepatology 52(6):1888-1896. doi:10.1002/hep.23912

Zeuzem S, Andreone P, Pol S, Lawitz E, Diago M, Roberts S et al (2011) Telaprevir for retreatment of HCV infection. N Engl J Med 364(25):24172428. doi:10.1056/NEJMoa1013086

\section{Submit your manuscript to a SpringerOpen ${ }^{\odot}$ journal and benefit from:}

- Convenient online submission

- Rigorous peer review

- Immediate publication on acceptance

- Open access: articles freely available online

- High visibility within the field

- Retaining the copyright to your article

Submit your next manuscript at springeropen.com 